\title{
Epidemiology of bicycle injuries and risk factors for serious injury
}

\author{
Frederick P Rivara, ${ }^{1}$ Diane C Thompson, ${ }^{2}$ Robert S Thompson ${ }^{3}$
}

${ }^{1}$ Harborview Injury Prevention and Research Center, Department of Pediatrics and Epidemiology, University of Washington, Seattle

${ }^{2}$ Harborview Injury Prevention and Research Center, Seattle ${ }^{3}$ Department of Preventive Care, Group Health

Cooperative of Puget Sound, Seattle

\section{Correspondence to:}

Professor FP Rivara,

Harborview Injury Preventional and Research Center, Box 359960, 325 Ninth Avenue, Seattle, WA 98014, USA.

In celebration of the 20th anniversary of Injury Prevention, we asked our readers and editorial board to identify six of the most influential papers available in the journal's archive. We will republish one of these in each of the six issues of the 2014 volume. In addition, current editorial board members have been asked to comment on the importance of the paper from a personal or professional perspective. We hope these highlights from past volumes will encourage you to explore the Injury Prevention archive on your own.

This is a reprint of a paper that first appeared in Injury Prevention, 1997, volume 3, pages $110-4$

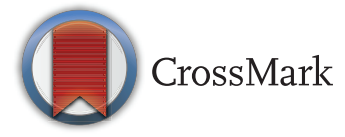

To cite: Rivara FP,

Thompson DC,

Thompson RS. Inj Prev

2015:21:47-51.
ABSTRACT

Objective To determine the risk factors for serious injury

to bicyclists, aside from helmet use.

Design Prospective case-control study.

Setting Seven Seattle area hospital emergency

departments and two county medical examiner's offices.

Patients Individuals treated in the emergency

department or dying from bicycle related injuries.

Measurements Information collected from injured

bicyclists or their parents by questionnaire on circumstances of the crash; abstract of medical records for injury data.

Serious injury defined as an injury severity score $>8$.

Analysis Odd ratios computed using the maximum likelihood method, and adjusted using unconditional logistic regression.

Results There were 3854 injured cyclists in the three year period; 3390 (88\%) completed questionnaires were returned. 51\% wore helmets at the time of crash. Only $22.3 \%$ of patients had head injuries and $34 \%$ had facial injuries. Risk of serious injury was increased by collision with a motor vehicle (odds ratio $(O R)=4.6)$, self reported speed $>15 \mathrm{mph}(\mathrm{OR}=1.2)$, young age ( $<6$ years), and age $>39$ years $(\mathrm{OR}=2.1$ and 2.2 respectively, compared with adults 20-39 years). Risk for serious injury was not affected by helmet use $(\mathrm{OR}=0.9)$. Risk of neck injury was increased in those struck by motor vehicles $(O R=4.0)$, hospitalized for any injury $(\mathrm{OR}=2.0)$, and those who died $(\mathrm{OR}=15.1)$, but neck injury was not affected by helmet use.

Conclusions Prevention of serious bicycle injuries cannot be accomplished through helmet use alone, and may require separation of cyclists from motor vehicles, and delaying cycling until children are developmentally ready.

There are 67 million bicyclists in the US, accounting for approximately 15 billion hours of riding per year. While bicycling is a wonderful recreational and exercise activity, it is not without its hazards. In the United States, the toll of bicycle injuries is approximately 900 deaths, 23000 hospital admissions, 580000 emergency department visits, and approximately 1.2 million physician office visits each year. ${ }^{1-3}$

There are now numerous reports in the literature on bicycle injuries from medical examiner offices, hospitals, and emergency departments. ${ }^{145}$ Much of the recent emphasis has been on head injuries and the protective effect offered by helmets. ${ }^{6-10}$ Nearly all reports on other injuries have been descriptive, with little analysis of the factors associated with types or severity of injury. The influence of factors such as age, motor vehicle involvement, and speed at the time of the crash on the severity of non-fatal injuries is largely unknown. Such information is necessary to develop prevention strategies for those bicyclist injuries not amenable to the effective protection offered by helmets.

This study encompasses the largest series of injured bicyclists reported to date and provides important information on the epidemiology of bicycle crashes and risk factors associated with severe injury.

\section{METHODS \\ DESIGN}

This study is part of a case-control study of bicycle injuries and helmet effectiveness, ${ }^{11}$ in which the main intent was to examine helmet use in head injured cases compared with controls with injuries not involving the head. In the present report, the case-control status of patients was ignored and all subjects were included in the analyses. Subjects were recruited from seven Seattle area hospitals; the records of the County Medical Examiners' (coroners') Offices were also examined during the study period to detect out-of-hospital deaths from bicycling occurring in the study catchment area.

\section{SUBJECT IDENTIFICATION}

Injured cyclists were identified by regular surveillance of emergency room logs (one hospital) or treatment forms (six hospitals) at least 1-2 times per week during the study period, 1 March 1992 through 31 August 1994. Any individual injured while on a bicycle (whether moving or not) was eligible (pedestrians injured by a bicycle were not included). Also excluded were individuals sustaining injuries from assault while riding a bicycle $(n=5)$. Child bicycle passengers under the age of 6 were included.

\section{DATA COLLECTION}

Detailed questionnaires were sent to all study subjects and those who did not respond were telephoned approximately 14 days after the initial mailing. The questionnaires included inquiries about demographic characteristics, cycling experience, circumstances of the crash, self reported speed, severity of damage to the bike, ownership and use of helmets, and helmet fit. Parents or guardians responded for subjects 14 and under.

Information on the injuries was gathered from the emergency department, hospital, and medical examiner's records by trained abstractors, using a standardized form. All hospital admissions were through the emergency room. The abbreviated injury scale (AIS) ${ }^{12}$ was used to assess the severity of injuries in individual body regions, and the injury severity score (ISS) ${ }^{13}$ was calculated and used as a measure of severity. This was done using TRI-CODE, a computer program that converts text 
injury descriptions into ICD-9 codes and calculates AIS and ISS scores. ${ }^{14}$ The TRI-CODE program provided consistent and accurate injury coding and scoring, given that the data were abstracted from seven different hospitals. ISS scores $>8$ were considered to be serious injuries.

\section{DATA ANALYSIS}

Data were double key entered, cleaned, and analyzed using SAS. ${ }^{15}$ Univariate analyses were conducted to examine associations between injury severity, crash, and demographic characteristics. TTie odds ratio (OR) and 95\% confidence interval $(\mathrm{Cl})$ were calculated using the maximum likelihood method and the Cornfield method, respectively. ${ }^{16}$ Unconditional logistic regression was used to calculate odds ratios adjusted for covariates found to be significant on univariate analyses or variables of special interest such as helmet use. ${ }^{17}$

\section{RESULTS}

Altogether 3849 eligible subjects were treated in the emergency rooms of the study hospitals and five subjects died from bicycle related injuries prior to emergency department arrival. We obtained completed questionnaires and injury data on 3390 subjects, a response rate of $88.0 \%$.

\section{CHARACTERISTICS OF THE STUDY POPULATION}

More than two thirds of the study population were male and $43.3 \%$ were under 13 years of age (table 1 ). Compared with the standard metropolitan statistical area (SMSA), our population of injury cyclists were more likely to be male, more likely to be a child or teen, and more likely to come from a household in which the head of the household had some postgraduate education. Household incomes were generally comparable between the subjects and the SMSA population.

Approximately two thirds bicycled daily. Among riders greater than 14 years old, 36\% rode more than 50 miles and $45 \%$ more than five hours per week.

Three fourths of the subjects (data not shown) reported that they owned bicycle helmets and 50.7\% reported helmet use at the time of the crash. Helmet use varied with age: $47.6 \%$ of those under age $5,44.7 \%$ of the $6-12$ year olds, $32.2 \%$ of the 13-19 year olds, and $63.8 \%$ of those 20 and over reported helmet use at the time of the crash.

\section{INJURIES SUSTAINED}

Approximately one half $(52.1 \%)$ of subjects sustained two or fewer injuries, $37.1 \%$ had three to five injuries, and $10.8 \%$ had more than five. Most commonly, cyclists sustained injuries to the upper extremities (59.6\%) and the lower extremities (46.9\%). Approximately one fifth $(22.3 \%)$ of cyclists had injuries to the head, defined as injuries to the scalp, skull, forehead or brain, and $34.8 \%$ had injuries to the face. Children under the age of 10 were more likely to sustain injuries to the head and face, while teens and young adults were more likely to sustain injuries to the extremities. Neck and trunk injuries showed no particular age patterns.

Injured riders most commonly had abrasions (60.7\%), lacerations (37.7\%) and contusions (36.5\%), but 30.6\% had fractures or dislocations and $12.3 \%$ sprains. Brain injuries, defined as a concussion or more serious brain injury, occurred to $6.0 \%$.

\section{INJURY SEVERITY}

A total of $93.2 \%$ had an ISS $\leq 8$ (that is no individual injury exceeding an AIS score of 2); $230(6.8 \%)$ had an ISS $\geq 9$. Of the 6088 injuries to extremities, $18.5 \%$ had an AIS score of $\geq 2$.
Table 1 Characteristics of the study population $(n=3390)$

\begin{tabular}{|c|c|c|}
\hline Characteristics & No $(\%)$ & $\%$ for SMSA (1990) \\
\hline \multicolumn{3}{|l|}{ Gender } \\
\hline Male & $2438(71.9)$ & 49.2 \\
\hline Female & $952(28.1)$ & 50.8 \\
\hline \multicolumn{3}{|l|}{ Age (in years) } \\
\hline$\geq 5$ & $252(7.4)$ & 8.3 \\
\hline $6-12$ & $1216(35.9)$ & 8.7 \\
\hline $13-10$ & $545(16.1)$ & 8.1 \\
\hline$>20$ & $1377(40.6)$ & 74.9 \\
\hline \multicolumn{3}{|c|}{ Education of head of the household* } \\
\hline$<$ High school & $178(5.3)$ & 11.8 \\
\hline High school & $490(14.5)$ & 22.8 \\
\hline Some college & $1012(29.9)$ & 24.9 \\
\hline College graduate & $847(25.0)$ & 30.5 \\
\hline Postgraduate & $807(23.8)$ & 10.1 \\
\hline Unknown & $56(1.7)$ & - \\
\hline \multicolumn{3}{|l|}{ Household income } \\
\hline$<\$ 10000$ & $453(13.4)$ & 9.9 \\
\hline$\$ 10000-24999$ & $670(19.8)$ & 22.3 \\
\hline$\$ 25000-49999$ & $966(28.5)$ & 36.1 \\
\hline$\$ 50000-99999$ & $803(23.7)$ & 25.9 \\
\hline$\geq \$ 100000$ & $224(6.6)$ & 5.9 \\
\hline Unknown & $275(8.1)$ & - \\
\hline \multicolumn{3}{|c|}{ Frequency of bicycling } \\
\hline Daily & $2102(62.0)$ & - \\
\hline Weekly & $884(26.1)$ & - \\
\hline Monthly & $157(4.6)$ & - \\
\hline$<$ Monthly & $74(2.2)$ & - \\
\hline Seldom & $163(4.8)$ & - \\
\hline Unknown & $10(0.3)$ & - \\
\hline \multicolumn{3}{|c|}{ No of miles/week bicycling ( $n=1609$; riders $\geq 15$ only) } \\
\hline$<10$ & $324(20.1)$ & - \\
\hline $10-49$ & $646(40.1)$ & - \\
\hline $50-99$ & $292(18.1)$ & - \\
\hline$\geq 100$ & $286(17.8)$ & - \\
\hline Missing data & $61(3.8)$ & \\
\hline
\end{tabular}

There were 318 patients (9.4\%) admitted to the hospital and 14 deaths total, of which nine occurred in the hospital and five at the scene.

\section{CIRCUMSTANCES OF THE CRASHES}

Motor vehicles were involved in only $15.3 \%$ of the crashes. More commonly, the rider lost control and hit the ground $(50.0 \%)$ or an obstacle $(29.0 \%)$. These events usually occurred on a street, and $76.6 \%$ occurred at speeds less than $15 \mathrm{mph}$. Bicycles were damaged in $43.5 \%$ of incidents.

\section{CORRELATION OF CRASH CIRCUMSTANCES WITH INJURY SEVERITY}

The relationship of circumstances of the crash with injury severity was initially examined by calculating the univariate $\mathrm{OR}$ to identify covariates for multivariate analysis. Involvement in a collision with a motor vehicle increased the risk of severe injury by 3.6-fold (table 2) and speed greater than $15 \mathrm{mph}$, by $40 \%$. Use of a helmet was only associated with a $10 \%$ decreased risk of severe injury, a difference which was not statistically significant. Individuals 40 and older and under age 12 had an elevated risk of severe injury, although this did not reach statistical 
Table 2 Univariate predictors of severe injury in bicycle crashes ( $\mathrm{n}=3390$ cyclists)*

\begin{tabular}{|c|c|c|c|c|}
\hline & $\begin{array}{l}\% \text { ISS }>8 \\
(n=232 ; 6.8 \%)\end{array}$ & $\begin{array}{l}\% \text { ISS } \leq 8 \\
(n=3158 ; 93.2 \%)\end{array}$ & OR & $95 \% \mathrm{Cl}$ \\
\hline \multicolumn{5}{|l|}{ Age (in years) } \\
\hline$\leq 5$ & 8.6 & 7.4 & 1.27 & 0.7 to 2.2 \\
\hline $6-12$ & 36.6 & 35.8 & 1.17 & 0.8 to 1.7 \\
\hline $13-19$ & 13.8 & 16.2 & 0.99 & 0.7 to 1.6 \\
\hline $20-39$ & 27.0 & 30.6 & 1.0 & Reference \\
\hline$\geq 40$ & 14.2 & 10.0 & 1.63 & 1.0 to 2.6 \\
\hline \multicolumn{5}{|l|}{ Crash characterstics } \\
\hline $\begin{array}{l}\text { Motor vehicle } \\
\text { involvement* }\end{array}$ & 36.1 & 13.7 & 3.6 & 2.7 to 4.7 \\
\hline Paved surfacet & 79.7 & 77.8 & 1.1 & 0.8 to 1.6 \\
\hline Speed >15 mph $\ddagger$ & 28.1 & 22.3 & 1.4 & 1.0 to 1.9 \\
\hline \multicolumn{5}{|l|}{ Gender } \\
\hline Male & 75.4 & 71.7 & 1.2 & 0.9 to 1.7 \\
\hline Female & 24.6 & 28.4 & 1.0 & Reference \\
\hline Helmet use & 52.6 & 49.1 & 0.9 & 0.7 to 1.2 \\
\hline
\end{tabular}

significance. Involvement with a motor vehicle markedly increased the risk of a fatal injury (OR 11.3, 95\% Cl 3.1 to 51.4). Only one of the fatally injured bicyclists was helmeted.

The most important predictor of admission to hospital was injury severity (table 3 ). Patients with an ISS $>8$ were 43.6 times more likely to be admitted than those with a lower ISS. As with other measures of severity, motor vehicle involvement increased the risk of admission nearly fourfold. Other significant risk factors for admission were male gender, age 40 years or older, and, to a lesser extent, age $<12$ years, crash on a paved surface, and self reported speed $>15 \mathrm{mph}$. To a lesser extent, age 40 years or older and age less than 12 years were also predictive of severe injury.

\section{MULTIVARIATE ANALYSIS: RISK FACTORS FOR SEVERE INJURY}

Logistic regression analysis was used to determine the individual effect of predictors for severe injury (ISS >8, $\mathrm{n}=232$ ) after adjusting for each of die other factors (table 4). Children under 12 years and cyclists 40 and older had the highest risk of severe injury, while teens and young adults had the lowest. Collision with a motor vehicle increased the risk of severe injury more than fourfold; crashes occurring at speeds estimated at $>15$ mph increased the risk by $20 \%$. Helmets had no apparent effect on the risk of severe injury, probably because head injuries accounted for fewer than one in six of all injuries and the majority of head injuries were not severe.

\section{NECK INJURY}

There were 91 individuals with neck injuries (table 5). Two thirds of neck injuries occurred to cyclists 20 and older, and $75 \%$ to males. Children and teens under the age of 19 were significantly less likely to have neck injuries than were adults 20 to 39 years. Collision with a motor vehicle increased the risk of a neck injury fourfold. Patients with neck injuries were much more likely to be severely injured $(\mathrm{OR}=4.09)$ and hospitalized $(\mathrm{OR}=2.56)$ than were patients without neck injuries. They were also 15 times more likely to die than those without neck injuries.

Of patients with neck injuries, 76 had neck sprains, 12 had cervical spine fractures, six had cord or nerve root injury, and
Table 3 Univariate predictors of hospital admission for treatment of bicycle related injury $(n=3385)$

\begin{tabular}{|c|c|c|c|c|}
\hline & $\begin{array}{l}\% \text { Admitted } \\
(n=342 ; 10.2 \%)\end{array}$ & $\begin{array}{l}\% \text { Not admitted } \\
(n=3043 ; 89.8 \%)\end{array}$ & OR & $95 \% \mathrm{Cl}$ \\
\hline \multicolumn{5}{|l|}{ Age (in years) } \\
\hline$\leq 5$ & 6.7 & 7.5 & 1.3 & 0.7 to 2.2 \\
\hline $6-12$ & 36.3 & 35.8 & 1.2 & 0.8 to 1.7 \\
\hline $13-19$ & 17.0 & 15.9 & 1.0 & 0.6 to 1.6 \\
\hline $20-39$ & 23.4 & 31.2 & 1.0 & Reference \\
\hline$\geq 40$ & 16.7 & 9.6 & 1.6 & 1.0 to 2.6 \\
\hline \multicolumn{5}{|l|}{ Gender } \\
\hline Male & 77.0 & 71.3 & 1.3 & 1.04 to 1.8 \\
\hline Female & 23.1 & 28.7 & 1.0 & Reference \\
\hline \multicolumn{5}{|c|}{ Crash characterstics } \\
\hline $\begin{array}{l}\text { Motor vehicle } \\
\text { involvement } †\end{array}$ & 36.0 & 12.8 & 3.8 & 3.0 to 4.9 \\
\hline Paved surface & 83.0 & 76.8 & 1.5 & 1.1 to 2.0 \\
\hline $\begin{array}{l}\text { Speed }>15 \\
\mathrm{mph} \S\end{array}$ & 29.0 & 21.8 & 1.5 & 1.2 to 1.9 \\
\hline \multicolumn{5}{|l|}{ ISS } \\
\hline$\leq 8$ & 52.0 & 97.9 & 1.0 & \\
\hline$>8$ & 48.0 & 2.1 & 43.6 & 31.0 to 61.3 \\
\hline Helmet use & 43.9 & 51.5 & 0.7 & 0.6 to 0.9 \\
\hline
\end{tabular}

${ }^{*}$ Five subjects who were dead at the scene of the crash were omitted. tReference group: all other crashes not involving moving motor vehicle. ‡Reference group: all unpaved surfaces.

§Reference group: speed $<15 \mathrm{mph}$.

one had injuries to blood vessels in the neck. There was no association of neck injury with helmet use, either in the entire group of patients with neck injury $(\mathrm{OR}=0.9,95 \% \mathrm{Cl} 0.6$ to 1.4 , adjusted for age), those with cervical spine fractures $(\mathrm{OR}=0.4$, $95 \% \mathrm{Cl} 0.1$ to 1.3 , adjusted for age), or those with sprains only $(\mathrm{OR}=0.9,95 \% \mathrm{Cl} 0.6$ to 1.5 adjusted for age). There was also no difference in risk of neck injury by helmet standard (ANSI, Snell, other) or type of helmet). The risk of neck injury was, however, markedly increased by the presence of a head injury $(\mathrm{OR}=2.7,95 \% \mathrm{Cl} 1.8$ to 4.1$)$ or a brain injury $(\mathrm{OR}=6.6,95 \%$ $\mathrm{Cl} 4.3$ to 10.4$)$.

\section{FATAL INJURIES}

There were 14 fatal injuries. The relationship between fatal injury and a series of potential risk factors was examined by

Table 4 Multivariate results: predictors of serious injury (ISS >8) in bicycle crashes*

\begin{tabular}{lll}
\hline Variable & OR & 95\% Cl \\
\hline Age in years & & \\
$\quad \leq 5$ & 2.1 & 1.2 to 3.8 \\
$6-12$ & 1.6 & 1.1 to 2.4 \\
$13-19$ & 1.1 & 0.7 to 1.7 \\
$20-39$ & 1.0 & Reference \\
$\geq 40$ & 2.2 & 1.4 to 3.5 \\
Motor vehicle involvement & 4.6 & 3.3 to 6.3 \\
Surface (other than paved) & 0.7 & 0.5 to 1.0 \\
Speed $>15$ mph & 1.2 & 1.0 to 1.5 \\
Wearing a helmet & 0.9 & 0.7 to 1.2 \\
\hline *Serious injury=ISS>8, $n=232$. & \\
Total subjects in the analysis=3343; 47 subjects excluded because of missing data for \\
one or more variables necessary for multivariate analysis.
\end{tabular}


Table 5 Risk factors for neck injuries

\begin{tabular}{|c|c|c|c|c|}
\hline & $\begin{array}{l}\% \text { Patients } \\
\text { with neck } \\
\text { injuries } \\
(n=91)\end{array}$ & $\begin{array}{l}\% \text { Patients } \\
\text { without neck } \\
\text { injuries } \\
(\mathrm{n}=3293)\end{array}$ & OR & $95 \% \mathrm{Cl}$ \\
\hline \multicolumn{5}{|l|}{ Gender } \\
\hline Male & 74.7 & 71.8 & 1.16 & 0.72 to 1.87 \\
\hline Female & 25.3 & 28.2 & 1.0 & Reference \\
\hline \multicolumn{5}{|l|}{ Age (in years) } \\
\hline$\leq 5$ & 1.1 & 7.6 & 0.07 & 0.00 to 0.50 \\
\hline $6-12$ & 15.4 & 36.4 & 0.22 & 0.12 to 0.41 \\
\hline 13-19 & 16.5 & 16.1 & 0.53 & 0.28 to 0.99 \\
\hline 20-39 & 57.1 & 29.7 & 1.0 & Reference \\
\hline$\geq 40$ & 9.9 & 10.3 & 0.50 & 0.23 to 1.06 \\
\hline $\begin{array}{l}\text { Motor vehicle } \\
\text { involvement }\end{array}$ & 40.7 & 14.6 & 4.01 & 2.56 to 6.29 \\
\hline $\mid S S>8$ & 21.9 & 6.4 & 4.09 & 2.37 to 7.04 \\
\hline Hospitalization & 17.6 & 9.6 & 2.56 & 1.57 to 4.19 \\
\hline Death & 4.4 & 0.3 & 15.12 & 6.23 to 36.70 \\
\hline Helmeted* & 52.8 & 50.6 & 1.09 & 0.72 to 1.65 \\
\hline Hard shell & 33.3 & 49.5 & 0.75 & 0.40 to 1.39 \\
\hline Thin shell & 35.4 & 28.6 & 1.38 & 0.75 to 2.52 \\
\hline No shell & 22.9 & 19.2 & 1.33 & 0.64 to 2.71 \\
\hline
\end{tabular}

univariate analysis; there were too few deaths to conduct multivariate analyses (table 6). Males were 2.4 times more likely, those hit by motor vehicles 14.1 times more likely, and those traveling at self reported speeds $>15 \mathrm{mph}, 2.6$ times more likely to be killed. Helmet use was associated with a $93 \%$ decrease in risk of fatality, which, alternatively stated, means that nonhelmeted riders were 14.3 times more likely to be involved in a fatal bicycle crash.

\section{DISCUSSION}

This study provides important information on the circumstances of bicycle crashes and the resultant injuries. The spectrum of these injuries treated in hospital emergency departments is

Table 6 Univariate predictrs of fatal injury in bicycle crashes

\begin{tabular}{|c|c|c|c|c|}
\hline & $\begin{array}{l}\% \text { Fatal } \\
(n=14 ; 0.4 \%)\end{array}$ & $\begin{array}{l}\% \text { Non-fatal } \\
(\mathrm{n}=3376 ; 99.6 \%)\end{array}$ & OR & $95 \% \mathrm{Cl}$ \\
\hline \multicolumn{5}{|l|}{ Age (in years) } \\
\hline$\leq 5$ & 0 & 7.5 & - & - \\
\hline $6-12$ & 42.9 & 35.8 & 1.0 & Reference \\
\hline 13-19 & 21.4 & 16.1 & 1.1 & 0.2 to 5.0 \\
\hline 20-39 & 35.7 & 30.3 & 0.98 & 0.3 to 3.6 \\
\hline$\geq 40$ & 0 & 10.3 & - & \\
\hline \multicolumn{5}{|l|}{ Gender } \\
\hline Female & 14.3 & 28.1 & 1.0 & Reference \\
\hline Male & 85.7 & 71.9 & 2.4 & 0.5 to 10.1 \\
\hline \multicolumn{5}{|c|}{ Crash characteristics } \\
\hline $\begin{array}{l}\text { Motor vehicle } \\
\text { involvement }^{*}\end{array}$ & 71.4 & 15.1 & 14.1 & 4.1 to 53.5 \\
\hline Paved surfacet & 78.6 & 77.5 & 1.1 & 0.3 to 4.8 \\
\hline $\begin{array}{l}\text { Speed }>15 \\
\text { mph } \neq\end{array}$ & 42.9 & 22.4 & 2.6 & 0.8 to 8.3 \\
\hline Helmet use & 7.1 & 50.9 & 0.07 & 0.02 to 0.35 \\
\hline
\end{tabular}

broad, and includes a large number of relatively minor contusions and abrasions, but, in addition, a substantial number of more severe injuries $(6.8 \%$ with ISS $>8)$ resulting in hospitalization or death. The most important predictors of injury severity appear to be motor vehicle involvement and self reported speed at the time of the crash while, as expected, the most important predictor of hospital admission, was injury severity. For fatal injuries, lack of use of a bicycle helmet or involvement with a motor vehicle in the crash were each associated with a 14-fold increase in fatality rate. However, helmet use was not associated with injury severity.

These data were based on a combination of self report by patients or parents and data abstracted from medical records. Self reported estimated speed, particularly when dichotomized between $\leq 15 \mathrm{mph}$ and $>15 \mathrm{mph}$, appears to be reliable when compared with actual radar measurements in recreational cyclists. ${ }^{18}$ While we have no direct validation of self reported helmet use, reported helmet use in our community appears to correlate well over the last eight years with actual use as measured by observations. ${ }^{19}$ Furthermore, in the present study helmet use was recorded in the emergency department for $52.5 \%$ of subjects. On this subset, the positive predictive value for helmet use reported on the questionnaire was $96.3 \%$ and the negative predictive value was $96.2 \%$, using the emergency department records as the 'gold standard'.

The use of medical records to determine actual injuries sustained provided more accurate data than that in some prior studies based on self report. Standardized methods to characterize injury severity also helped improve data reliability.

The study population was younger and better educated than the population of the surrounding SMSA and was also composed of a large number of cyclists who reported cycling daily, and more than one third who reported cycling more than 50 miles per week. Since the data were obtained from a sizable and geographically distributed emergency department sample in the Seattle-Tacoma metropolitan area, we believe the data are representative of the population of cyclists in this area. Thus, the injuries in this population may not be representative of a population who bicycle less, or under different circumstances, or in other regions of the country where cycling practices may differ.

The finding of motor vehicle involvement as an important predictor of severe and fatal injury fits well with prior reports on cycling and those on pedestrian injuries involving motor vehicles. $^{20} 21$ Separating bicycles from the roadway by encouraging bicycling on bicycle paths or sidewalks may not be a solution to this problem, because of the increased risks to cyclists at the intersection of bike paths and sidewalks with roads. ${ }^{22}$

The fact that speed is also related to risk of severe and fatal injury fits well with motor vehicle data and the laws of physics. Energy transfer to the bicyclist is greater at higher speeds unless measures are taken to reduce this transfer of energy. The effect of other types of protective equipment on speed related injury to bicyclists is unknown.

The fact that younger cyclists were at twofold increased risk for serious injury is of concern. Even after controlling for motor vehicle involvement, children 12 and under have twice the risk of serious injury as do adults over the age of 20-39 years. This indicates that these children may be attempting to ride before they are developmentally ready, that the bicycle does not fit their size, or that the site where they ride (that is, in traffic) may be unsafe or poorly supervised. The reasons for the similarly increased risk of those 40 and older are unknown, but may be partially explained by increased physical fragility with increasing age. 
Head injuries constituted a much lower proportion of all injuries than in prior reports, including our previous case-control study. ${ }^{6}$ In that study, $34.7 \%$ of individuals treated for bicycle injuries had injuries to the head and $12.8 \%$ had injuries to the brain. In the present study, conducted during 1992-4, in those same five hospital emergency departments plus two additional hospitals, $22.3 \%$ of patients had injuries to the head and $6.0 \%$ injuries to the brain. We have previously documented a more than two thirds reduction in population based rates of emergency department treated head injuries among children from a large health maintenance organization over this period of time associated with increases in community wide helmet wearing rates. ${ }^{19}$ We believe these data provide further support for the effectiveness of community based helmet promotion programs.

There was no evidence that helmets affected the risk of neck injury either positively or negatively. While some have suggested that motorcycle helmets increase the risk of neck injury, data from other studies on motorcycle helmets indicate otherwise. ${ }^{23}$

The large numbers of facial injuries (35\% of cyclists) are a cause for concern. In a separate report based on this same series of injuries however, we demonstrated a $65 \%$ reduction in upper and mid-face injuries from helmets. ${ }^{24}$ Thus, no helmet modification appears indicated for the general cyclist. But there may be a need for manufacturers to consider additional face protection on helmets for certain high risk groups such as children, young adults, and those riding off-road or in traffic. Indeed, this has happened for off-road riders at present.

The number of extremity injuries is large and, of course, is not affected by helmet promotion campaigns. Over 1000 of these injuries were fractures or dislocations, resulting in some immediate disability. The frequency of these injuries again dictates that other approaches to prevention be implemented, as discussed above. The effectiveness of elbow, knee pads, and wrist guards should be investigated, particularly in light of recent information showing their powerful protective effects for in-line skates. ${ }^{25}$

The tenets of injury control teach that many different strategies are available to decrease their occurrence and severity. Bicycle related trauma is one problem amenable to many approaches, including educational programs, product modification, modification of bicycle path crossing points, regulation, or legislation. The number and severity of these injuries indicates that further development of interventions are warranted.

Acknowledgements Supported by a grant from the Snell Memorial Foundation.

\section{REFERENCES}

1 Sacks JJ, Holmgreen P, Smith SM, Sosin DM. Bicycle-associated head injuries and deaths in the United States from 1984 through 1988. How many are preventable? JAMA 1991;266:3016-8.
2 Rodgers GB. Bicycle use and hazard patterns in the United States. Washington, DC: US Consumer Product Safety Commission, 1994.

3 Thompson DC, Dannenberg AL, Thompson RS, Rivara FP. Bicycling. In: Caine C, Caine D, Lindner K. eds. Epidemiology of sports injuries. Champaign, IL: Human Kinetics Publishers, 1996:98-112.

4 Baker SP, Li G, Fowler C, Dannenberg AL. Injuries to bicyclists: a national perspective. Baltimore, MD: The Johns Hopkins University Injury Prevention Center, 1993.

5 Friede AM, Azzard CV, Gallagher SS, Guyer B. The epidemiology of injuries to bicycle riders. Pediatr Clin North Am 1985;32:141-51.

6 Thompson RS, Rivara FP, Thompson DC. A case-control study of the effectiveness of bicycle-safety helmets. N Engl J Med 1989;320:1361-7.

7 McDermott FT, Lane FC, Brazenor GA, Debney EA. The effectiveness of bicyclist helmets: a study of 1710 casualties. J Trauma 1993;34:834-45.

8 Maimaris $C$, Summers CL, Browning C, Palmer CR. Injury patterns in cyclists attending an accident and emergency department: a comparison of helmet wearers and nonwearers. BMJ 1994:308:1537-40.

9 Henderson M. The effectiveness of bicycle helmets - a review. New South Wales: Bicycle Helmet Safety Institute, 1995.

10 Thomas S, Acton C, Nixon J, Battisutta D, Pitt WR, Clark R. Effectiveness of bicycle helmets in preventing head injury in children: a case-control study. BMJ 1994;308:173-6.

11 Thompson DC, Rivara FP, Thompson RS. Effectiveness of bicycle helmets in preventing head injuries. JAMA 1996;276:1968-73.

12 Association for the Advancement of Automotive Medicine. The abbreviated injury scale, 1990 revision. Des Plaines, IL: AAAM, 1990.

13 Baker SP, O'Neill B, Haddon W, Long WB. The injury severity score: a method for describing patients with multiple injuries and evaluating emergency care. J Trauma 1974;14:187-96.

14 Tri-Code 5.0. Personal computer injury coding software. Bel Air, MD: Tri-Analytics Inc, 1989.

15 SAS Institute Inc. SAS language and procedures: usage. Version 6, first edition. Cary, NC: SAS Institute Inc, 1989.

16 Cornfield JA. Statistical problem arising form retrospective studies. In: Neyman J, ed. Proceedings of the Third Berkeley Symposium. Berkeley: University of California Press, 1956;4:135-48

17 Brelsow NE, Day NE. The analysis of case-control studies. Statistical methods in cancer research. Vol 1. Lyon, France: International Agency for Research on Cancer, 1980:190-246. (IARC Scientific Publication No 32.).

18 Thompson DC, Rebolledo V, Thomson RS, et al Bike speed measurement in a recreational population: validity of self reported speed. Injury Prevention 1997;3:43-5.

19 Rivara FP, Thompson DC, Thompson RS et al The Seatde children's bicycle helmet campaign: changes in helmet use and head injury admissions. Pediatrics 1994;93:567-9

20 Fife D, Davis J, Tate L, Wells JK, Mohan D, Williams A. Fatal injuries to bicyclists: the experience of Dade County, Florida. J Trauma 1983;23:745-55.

21 Rivara FP. Child pedestrian injuries in the United States. Current status of the problem, potential interventions, and future research needs. Am J Dis Child 1990;144:692-6.

22 Wachtel A, Lewiston D. Risk factors for bicycle-motor vehicle collisions at intersections. Institute of Transport Engineers Journal 1994;64:30-2.

23 Shankar BS, Ramzy Al, Söderström CA, et al Helmet use, patterns of injury, medical outcome and costs among motorcycle drivers in Maryland. Accid Anal Prev 1993:24:385-96.

24 Thompson DC, Nunn ME, Thompson RS, Rivara FP. Effectiveness of bicycle-safety helmets in preventing serious facial injury. JAMA 1996;276:1974-5.

25 Schieber RA, Branche-Dorsey B, Ryan GW, Rutherford GW, Stevens JA, O'Neil J. Risk factors for injuries from in-line skating and the effectiveness of safety gear. N Engl J Med 1996;335:1630-5. 